\title{
Aspects Regarding the Relationship Between the Stability of Six Magnesium Compounds and their Cellular Uptake in Mice
}

\author{
CORINA MOISA ${ }^{1}$, SIMONA BUNGAU ${ }^{1 *}$, TAPAN BEHL ${ }^{2 *}$, FLORIN BANICA ${ }^{1}$, \\ LAVINIA PURZA ${ }^{1}$, RADU DUMITRU MOLERIU ${ }^{3}$, OANA CADAR ${ }^{4}$, \\ OVIDIU FRATILA ${ }^{5}$, DELIA MIRELA TIT ${ }^{1}$
}

${ }^{1}$ University of Oradea, Faculty of Medicine and Pharmacy, Department of Pharmacy, 29 N. Jiga Str., 410028, Oradea, Romania

${ }^{2}$ Chitkara College of Pharmacy, Chitkara University, 140401 Punjab, India

${ }^{3}$ West University of Timisoara, Faculty of Mathematics and Computer Science, Department of Mathematics, Romania ${ }^{4}$ INCDO-INOE 2000, Research Institute for Analytical Instrumentation, 67 Donath Str., 400293, Cluj Napoca, Romania

${ }^{5}$ University of Oradea, Faculty of Medicine and Pharmacy, Department of Medical Discipline, 101 Decembrie Sq., 410073, Oradea, Romania

\begin{abstract}
This research establishes the relationship between the influence of the stability of 6 magnesium compounds on their cellular uptake and focuses on the comparation between them, finding out which is the magnesium compound with the best bioavailability, depending on the stability. $\mathrm{Mg}^{2+}$ was dosed from tissues taken from various mice organs after the administration of compounds containing it, during the shelf life of the compounds, respectively at 6/12 months after their expiration. Different quantities of substances were also used - 25/50/100/200/300 mg/day/mouse, in groups of 2 mice for each dose. The samples were administered by gavage, following in parallel the possible side effects that may occur. During the shelf life of the compounds and at 6 months after expiration, in all organs, the lowest value was obtained for magnesium oxide and the highest value was detected for magnesium citrate. At 12 months after expiration, in all organs, the lowest/highest value was obtained in the case of oxide/orotate, respectively. It was found that the highest concentration of magnesium is stored in the spleen and lowest in lungs. The data obtained demonstrated a good stability of the tested substances (indicated by maintaining the cellular uptake rate) even 6 months after the expiration date.
\end{abstract}

Keywords: magnesium compounds, stability, absorption, shelf life, therapeutic efficiency

\section{Introduction}

Magnesium is a cation with predominant intracellular localization, only $1 \%$ of $\mathrm{Mg}^{2+}$ is found in the extracellular fluid, most of it being in the form of free ions and the rest being linked to plasma proteins [1]. Some of the main functions of magnesium in human biology include the preservation of ionic gradients (keeping intracellular sodium and calcium low and potassium high), cellular and tissue integrity, mitochondrial oxidative phosphorylation (ATP production and activation) and DNA, RNA and protein synthesis and integrity [2]. Along with sodium, potassium and calcium, $\mathrm{Mg}^{2+}$ regulates neuromuscular excitability and the coagulation mechanism [3]. At the intracellular level, the values of $\mathrm{Mg}^{2+}, \mathrm{Ca}^{2+}$ and $\mathrm{K}^{+}$are correlated with each other. Therefore, they are relevant for the proper functioning of the whole organism and the modification of the serum level of $\mathrm{Mg}^{2+}$ determines the serum variations of other ions values [4].

Hypomagnesemia is associated with an increased risk of cardiac arrhythmia, through a mechanism that is related to the low effect of $\mathrm{Mg}^{2+}$, causing $\mathrm{Na}^{+} / \mathrm{K}^{+}$-ATPase damage, lowering intracellular $\mathrm{K}^{+}$ levels, increasing intracellular $\mathrm{Na}^{+}$and creating a negative potential for the resting membrane. This mechanism leads to unstable membrane potentials and impulse conduction, which results in an increased susceptibility to arrhythmia [5,6]. Patients with congestive heart failure are more prone to low levels of serum potassium and magnesium in the body, some studies indicating that a low level of magnesium, in the case of patients with heart failure, exceeds $30 \%$. 
An analysis of studies on 5172 patients with total heart failure showed that hypermagnesemia $(\geq 1.55$ $\mathrm{mmol} / \mathrm{L}$ ) was associated with an increased risk of cardiovascular mortality [7]. Other studies have shown a significant decrease in arrhythmias after the treatment for hypomagnesemia (using intravenous magnesium sulfate) [8-10].

Some specialists associate hypomagnesemia with chronic lung disease and increased disease severity $[11,12]$. However, no significant therapeutic effect of intravenous or inhaled magnesium used in the treatment of chronic obstructive pulmonary disease (COPD) has been demonstrated [13].

Restoring the magnesium deficiency as well as the intracellular values of $\mathrm{Ca}^{2+}, \mathrm{K}^{+}$and $\mathrm{Na}^{+}$, depend on the source of magnesium used in therapy [14]. Studies on various drugs/supplements/ pharmaceuticals containing magnesium in form of different salts have indicated variations in magnesium uptake at the intracellular level and different concentrations of magnesium in various organs. Depending on the preparation administered, clinical studies have shown that only about $30-40 \%$ of the administered magnesium is absorbed, the absorption varies depending on the amount of magnesium administered and the compound found in the supplement/drug/preparation used in therapy. The excipients also have an important role in the absorption of magnesium from various drugs besides the nature of the compounds that contain this cation [15]. Therefore, pharmaceutical preparations with magnesium must have a high bioavailability and the highest possible stability over time, maintaining all biopharmaceutical and pharmaco-technic properties. Moreover, given the current context of drug pollution in all environmental sectors and its devastating effects [16,17], obtaining pharmaceutical preparations with as much stability as possible over time and with high bioavailability must be a priority in pharmaceutical practice.

This research analyzed the variation of the intracellular concentration of the Mg ions, in different organs, depending on the administered compounds and their concentration. The aim of the study was to determine the cellular uptake rate of five magnesium salts and one magnesium oxide, administered in different quantities/concentrations, at compound being in term and at $6 / 12$ months after expiration. The obtained results can represent a starting point in the development and implementation of new and modern concepts for formulating pharmaceutical products containing magnesium.

\section{Materials and methods}

\subsection{Subjects and environment}

Grown-up male mice $(n=72) \mathrm{Crl}: C D 1(I C R)$, with average weight of $26.92 \pm 0.21 \mathrm{~g}$, were used in conditions of acclimatization and quarantine. The mice were kept in open-top cages, in controlled environment (relative humidity of $55 \pm 10 \%$, standard temperature of $22 \pm 2^{\circ} \mathrm{C}$ ) following a cycle of $12 / 12$ hours dark/light, light intensity of $300 \mathrm{~lx}$ (lights on at 7 a.m.). The groups of subjects were randomly placed in different cages and each subject was marked on the base of the tail using permanent markers.

The experiments were carried out according to the EU Directive 63/2010 and were authorized by the Ethics Committee of the "Iuliu Hatieganu" University of Medicine and Pharmacy, Cluj Napoca, Romania. The research followed the ARRIVE guidelines concerning animals research and the subjects were treated in concordance with the European and Romanian guidelines.

\subsection{Procedure and data collection}

The subjects were administered quantities of 25/50/100/200/300 mg/day/mouse, single-dose pure magnesium orotate $\left(\mathrm{C}_{10} \mathrm{H}_{6} \mathrm{MgN}_{4} \mathrm{O}_{8}\right.$, from Sigma-Adrich, Germany), magnesium chloride $\left(\mathrm{MgCl}_{2} \cdot 6 \mathrm{H}_{2} \mathrm{O}\right)$, magnesium sulphate $\left(\mathrm{MgSO}_{4} \cdot 7 \mathrm{H}_{2} \mathrm{O}\right)$, magnesium carbonate $\left(\mathrm{MgCO}_{3}\right)$, magnesium citrate $\left(\mathrm{Mg}_{3}\left(\mathrm{C}_{6} \mathrm{H}_{5} \mathrm{O}_{7}\right)_{2}\right.$ and magnesium oxide $(\mathrm{MgO})$ (all the last 5 substances produced by $\mathrm{ZIBO}$ JINXING CHEMICAL CO., LTD, China), dispersed in distilled water, orally, through flexible plastic feeding tubes. In this research, administrated doses of magnesium compounds were chosen taking into account that these are the usual doses in which the tested magnesium compounds are used in dietary supplements. Every dose was administered to a group of 2 subjects (with a total of 10 mice for each compound). In other words, the amount of magnesium absorbed by dose was evaluated to identify the optimal dose of each compound, but the comparative study on the bioavailability of the compounds was 
performed using the average amount of magnesium in each organ for all doses administered (practically, the results from 10 mice were taken into account).

The subjects in the control group were given distilled water. After an interval of $2 \mathrm{~h}$ since treatment administration, the subjects were euthanized through the cervical dislocation procedure, then the internal organs (lungs, kidneys, liver, heart, spleen) were collected. Every organ was weighed, and the result was registered. The $\mathrm{Mg}$ content of every organ was detected with an inductively coupled plasma optical emission spectrometer (ICP-OES) Optima 5300 DV (Perkin Elmer, USA), after the digestion. The digestion was done on $200 \mathrm{mg}$ organ tissue with a combination of $\mathrm{HNO}_{3} 65 \%$ and $\mathrm{H}_{2} \mathrm{O}_{2} 30 \%$ (10:1, v:v) in a sealed PTFE vessel microwave digestion system (Berghof MWS-3+, Eningen, Germany) following the procedure presented by Zhao et al [18]. The whole amount of the digested probes was put in volumetric flasks of $10 \mathrm{~mL}$ and ultrapure water was added to the mark. Each probe was subjected to three repeated measurements. The calibrators for ICP-OES measurements were obtained by adequate dilutions of $1000 \mathrm{mg} / \mathrm{L}$ multielement IV ICP solution (Merck, Germany). Deionized water (18.2 $\mathrm{M} \Omega / \mathrm{cm}$ ) from Millipore Direct-Q3 UV Ultrapure water system (Millipore, Molsheim, France) was used to prepare the dilutions.

\subsection{Statistical analysis}

The database was gathered using a Microsoft Excel program. For this study, descriptive analyses were run. In order to see whether the observed differences are statistically significant, the following tests were applied: Mann - Whitney test, Kruskal Wallis test and ANOVA One Way test; for data distribution, the Shapiro Wilcoxon test was run. The level of significance was set at $\alpha=0.05$. The SPSSv19 program was used for the statistical analysis.

\section{Results and discussions}

In the first part of the statistics, the data characteristics were presented using tables or plots/charts. For data representation, a line graphic was used. Because this study has a special characteristic given by the small sample size, the best way to observe the data was to plot the mean value obtained from the experimental data, knowing that each organ has a different way to collect/store the magnesium compounds. All the results are presented in Tables 1-3.

Table 1. Magnesium concentration in organs after administration of magnesium compounds in the shelf life

\begin{tabular}{|c|c|c|c|c|c|c|}
\hline \multirow{2}{*}{$\begin{array}{l}\text { Administered dose } \\
(\mathbf{m g})\end{array}$} & \multicolumn{6}{|c|}{ Compounds of $\mathrm{Mg}$ (mg/kg/studied organ) } \\
\hline & Orotate & Sulphate & Oxide & Chloride & Carbonate & Citrate \\
\hline \multicolumn{7}{|c|}{ Heart } \\
\hline 25 & 145 & 130 & 122 & 140 & 137 & 152 \\
\hline 50 & 150 & 140 & 125 & 145 & 140 & 160 \\
\hline 100 & 160 & 155 & 144 & 160 & 150 & 170 \\
\hline 200 & 171 & 160 & 154 & 170 & 161 & 185 \\
\hline 300 & 168 & 135 & 130 & 165 & 155 & 180 \\
\hline \multicolumn{7}{|c|}{ Spleen } \\
\hline 25 & 200 & 193 & 191 & 196 & 194 & 210 \\
\hline 50 & 210 & 210 & 200 & 210 & 200 & 220 \\
\hline 100 & 220 & 153 & 152 & 218 & 215 & 232 \\
\hline 200 & 230 & 229 & 228 & 225 & 220 & 243 \\
\hline 300 & 220 & 200 & 216 & 220 & 215 & 239 \\
\hline \multicolumn{7}{|c|}{ Kidneys } \\
\hline 25 & 180 & 145 & 130 & 175 & 170 & 185 \\
\hline 50 & 186 & 150 & 131 & 185 & 173 & 201 \\
\hline 100 & 195 & 160 & 130 & 203 & 181 & 218 \\
\hline
\end{tabular}




\begin{tabular}{|c|c|c|c|c|c|c|}
\hline 200 & 210 & 180 & 150 & 215 & 190 & 235 \\
\hline 300 & 198 & 130 & 139 & 201 & 185 & 221 \\
\hline \multicolumn{7}{|c|}{ Lungs } \\
\hline 25 & 115.8 & 79.1 & 75.6 & 110 & 105.1 & 120.2 \\
\hline 50 & 120.9 & 88 & 83.8 & 115.2 & 110.8 & 131.5 \\
\hline 100 & 134.5 & 90.1 & 87.6 & 122 & 119.9 & 162.4 \\
\hline 200 & 140.8 & 102 & 98.3 & 131.5 & 125.4 & 170.6 \\
\hline 300 & 150.8 & 89.3 & 90.4 & 120.8 & 115 & 160.1 \\
\hline \multicolumn{7}{|c|}{ Liver } \\
\hline 25 & 160.5 & 145 & 142 & 155.2 & 150 & 170.1 \\
\hline 50 & 165.8 & 149 & 152 & 161 & 155 & 179.2 \\
\hline 100 & 179 & 151 & 157 & 172 & 160 & 191.5 \\
\hline 200 & 191 & 160 & 158 & 185 & 175 & 220.3 \\
\hline 300 & 201.3 & 145 & 113 & 165 & 160.6 & 215.8 \\
\hline
\end{tabular}

Table 2. Intracellular concentrations of $\mathrm{Mg}^{2+}$ in different organs, following the administration of magnesium compounds, 6 months after the expiry date

\begin{tabular}{|c|c|c|c|c|c|c|}
\hline \multirow{2}{*}{$\begin{array}{l}\text { Administered } \\
\text { dose (mg) }\end{array}$} & \multicolumn{6}{|c|}{ Compounds of $\mathrm{Mg}(\mathrm{mg} / \mathrm{kg} /$ studied organ) } \\
\hline & Orotate & Sulphate & Oxide & Chloride & Carbonate & Citrate \\
\hline \multicolumn{7}{|c|}{ Heart } \\
\hline 25 & 145 & 130 & 120 & 140 & 137 & 147 \\
\hline 50 & 150 & 140 & 122 & 145 & 140 & 155 \\
\hline 100 & 160 & 155 & 141 & 160 & 150 & 165 \\
\hline 200 & 171 & 160 & 151 & 170 & 161 & 180 \\
\hline 300 & 168 & 135 & 128 & 165 & 155 & 175 \\
\hline \multicolumn{7}{|c|}{ Spleen } \\
\hline 25 & 200 & 193 & 188 & 196 & 194 & 206 \\
\hline 50 & 210 & 210 & 196 & 210 & 200 & 216 \\
\hline 100 & 220 & 153 & 149 & 218 & 215 & 227 \\
\hline 200 & 230 & 229 & 223 & 225 & 220 & 238 \\
\hline 300 & 220 & 200 & 212 & 220 & 215 & 231 \\
\hline \multicolumn{7}{|c|}{ Kidneys } \\
\hline 25 & 180 & 145 & 127 & 175 & 170 & 180 \\
\hline 50 & 186 & 150 & 128 & 185 & 173 & 195 \\
\hline 100 & 195 & 160 & 127 & 203 & 181 & 211 \\
\hline 200 & 210 & 180 & 147 & 215 & 190 & 228 \\
\hline 300 & 198 & 130 & 136 & 201 & 185 & 214 \\
\hline \multicolumn{7}{|c|}{ Lungs } \\
\hline 25 & 115.8 & 79.1 & 74.08 & 110 & 105.1 & 116.6 \\
\hline 50 & 120.9 & 88 & 82.15 & 115.2 & 110.8 & 127.55 \\
\hline 100 & 134.5 & 90.1 & 85.72 & 122 & 119.9 & 157.43 \\
\hline 200 & 140.8 & 102 & 96.12 & 131.5 & 125.4 & 165.48 \\
\hline 300 & 150.8 & 89.3 & 88.6 & 120.8 & 115 & 155.1 \\
\hline \multicolumn{7}{|c|}{ Liver } \\
\hline 25 & 160.5 & 145 & 139 & 155.2 & 150 & 165 \\
\hline 50 & 165.8 & 149 & 149 & 161 & 155 & 173 \\
\hline 100 & 179 & 151 & 154 & 172 & 160 & 185 \\
\hline 200 & 191 & 160 & 155 & 185 & 175 & 213 \\
\hline 300 & 201.3 & 145 & 110 & 165 & 160.6 & 209 \\
\hline
\end{tabular}


Table 3. Intracellular concentrations of $\mathrm{Mg}^{2+}$ in different organs, following the administration of magnesium compounds, 12 months after the expiry date

\begin{tabular}{|c|c|c|c|c|c|c|}
\hline \multirow{2}{*}{$\begin{array}{l}\text { Administered } \\
\text { dose (mg) }\end{array}$} & \multicolumn{6}{|c|}{ Compounds of $\mathrm{Mg}$ (mg/kg/studied organ) } \\
\hline & Orotate & Sulphate & Oxide & Chloride & Carbonate & Citrate \\
\hline \multicolumn{7}{|c|}{ Heart } \\
\hline 25 & 120 & 104 & 86 & 105 & 98 & 96 \\
\hline 50 & 124 & 112 & 87 & 108 & 100 & 100 \\
\hline 100 & 132 & 124 & 100 & 120 & 108 & 107 \\
\hline 200 & 142 & 128 & 108 & 127 & 116 & 114 \\
\hline 300 & 140 & 108 & 91 & 123 & 111 & 111 \\
\hline \multicolumn{7}{|c|}{ Spleen } \\
\hline 25 & 166 & 155 & 134 & 147 & 140 & 132 \\
\hline 50 & 175 & 168 & 140 & 157 & 144 & 139 \\
\hline 100 & 183 & 122 & 106 & 163 & 155 & 146 \\
\hline 200 & 190 & 184 & 160 & 168 & 158 & 153 \\
\hline 300 & 183 & 160 & 151 & 165 & 155 & 150 \\
\hline \multicolumn{7}{|c|}{ Kidneys } \\
\hline 25 & 150 & 116 & 91 & 131 & 122 & 116 \\
\hline 50 & 158 & 120 & 92 & 138 & 125 & 126 \\
\hline 100 & 162 & 128 & 90 & 152 & 130 & 137 \\
\hline 200 & 175 & 144 & 105 & 161 & 137 & 148 \\
\hline 300 & 165 & 104 & 97 & 150 & 140 & 140 \\
\hline \multicolumn{7}{|c|}{ Lungs } \\
\hline 25 & 96 & 63 & 53 & 82 & 75 & 75 \\
\hline 50 & 102 & 70 & 59 & 86 & 80 & 83 \\
\hline 100 & 113 & 72 & 61 & 90 & 86 & 102 \\
\hline 200 & 118 & 82 & 68 & 98 & 90 & 105 \\
\hline 300 & 127 & 72 & 63 & 90 & 82 & 101 \\
\hline \multicolumn{7}{|c|}{ Liver } \\
\hline 25 & 136 & 116 & 99 & 117 & 108 & 107 \\
\hline 50 & 139 & 119 & 110 & 124 & 111 & 113 \\
\hline 100 & 150 & 124 & 110 & 127 & 115 & 118 \\
\hline 200 & 160 & 130 & 109 & 138 & 126 & 143 \\
\hline 300 & 169 & 116 & 80 & 127 & 115 & 140 \\
\hline
\end{tabular}

Applying the Shapiro - Wilk test for the distribution of the obtained data, it turned out that the results do not have a normal distribution ( $\mathrm{p}<\alpha=0.05)$; so, in this study, were used non-parametrical tests. As it can be observed from tables 1-3, there is a minor change in the magnesium compounds absorption when the shelf life is exceeded with 6 months, but the major changes are registered after it is exceeded with 12 months. In order to test this difference, a simple calculation can be done: the values of the magnesium absorbed at 6 , respectively 12 months after the shelf life was exceeded, were subtracted from the values of the magnesium absorbed (being in the shelf life), and these values were compared applying a Mann - Whitney test. In all tested organs and for all the dilutions, it resulted insignificant differences between shelf life and 6 months after exceeding it ( $p>0.05)$ and extremely significant differences between shelf life and 12 months after exceeding it $(\mathrm{p}<0.001)$. Also, these major differences are presented in Figures 1 and 2a-g. It was chosen a line chart representation because it allows easily observation of data variance and it highlights the data dynamics within the organs in three different time points. 


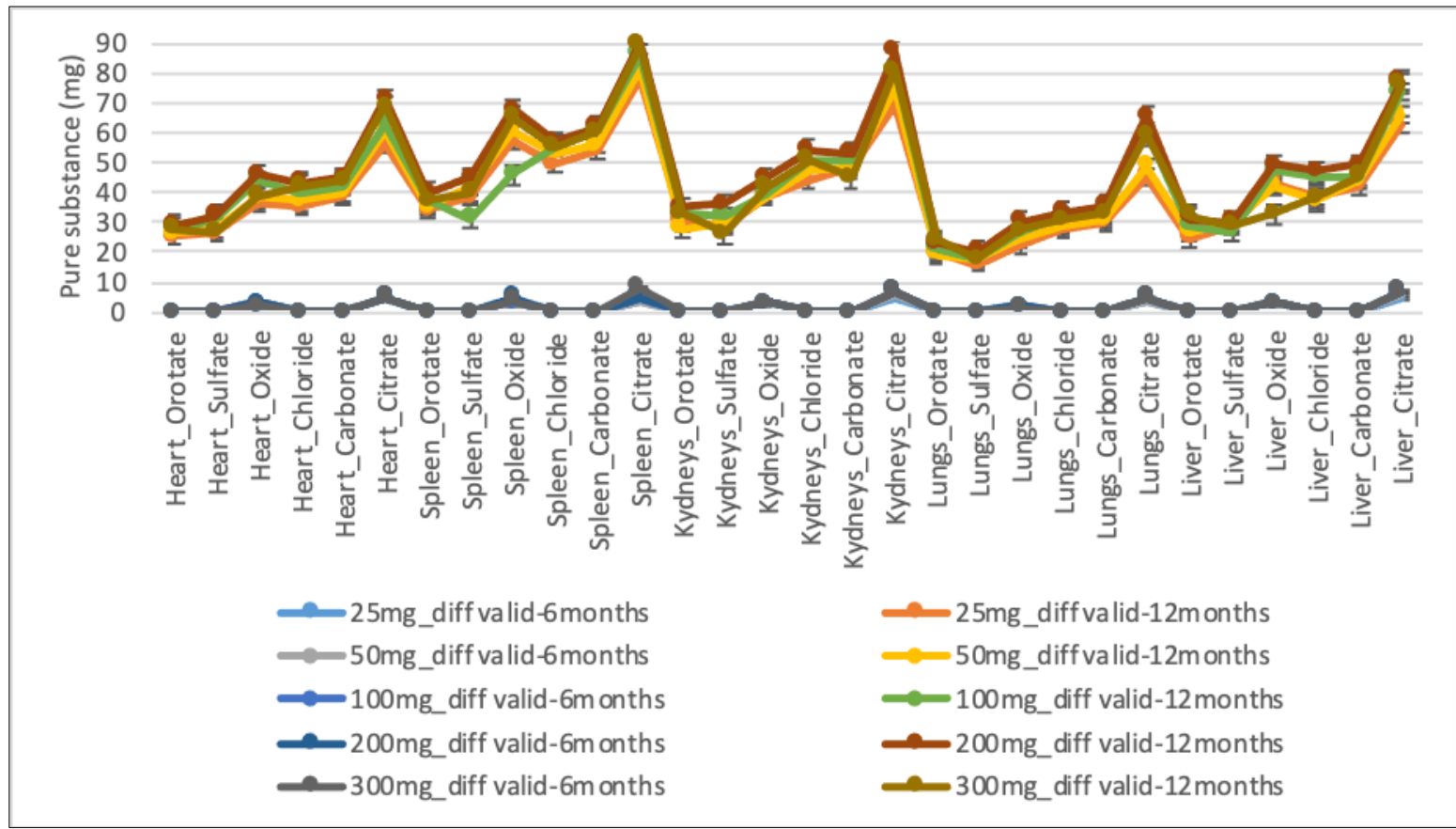

Figure 1. The differences between the magnesium concentration in organs, after administration of magnesium compounds within shelf life, after the it was exceeded with 6/12 months. The line close to zero represents the differences between the magnesium compounds in the shelf life and after 6 months, which means that these two values of absorption are almost equal. The second line, which is between (18-90 mg) represents the differences between the magnesium compounds in the shelf life and after 12 months. From this second line it can be seen that, if the shelf life is exceeded with 12 months, the level of absorption is much smaller

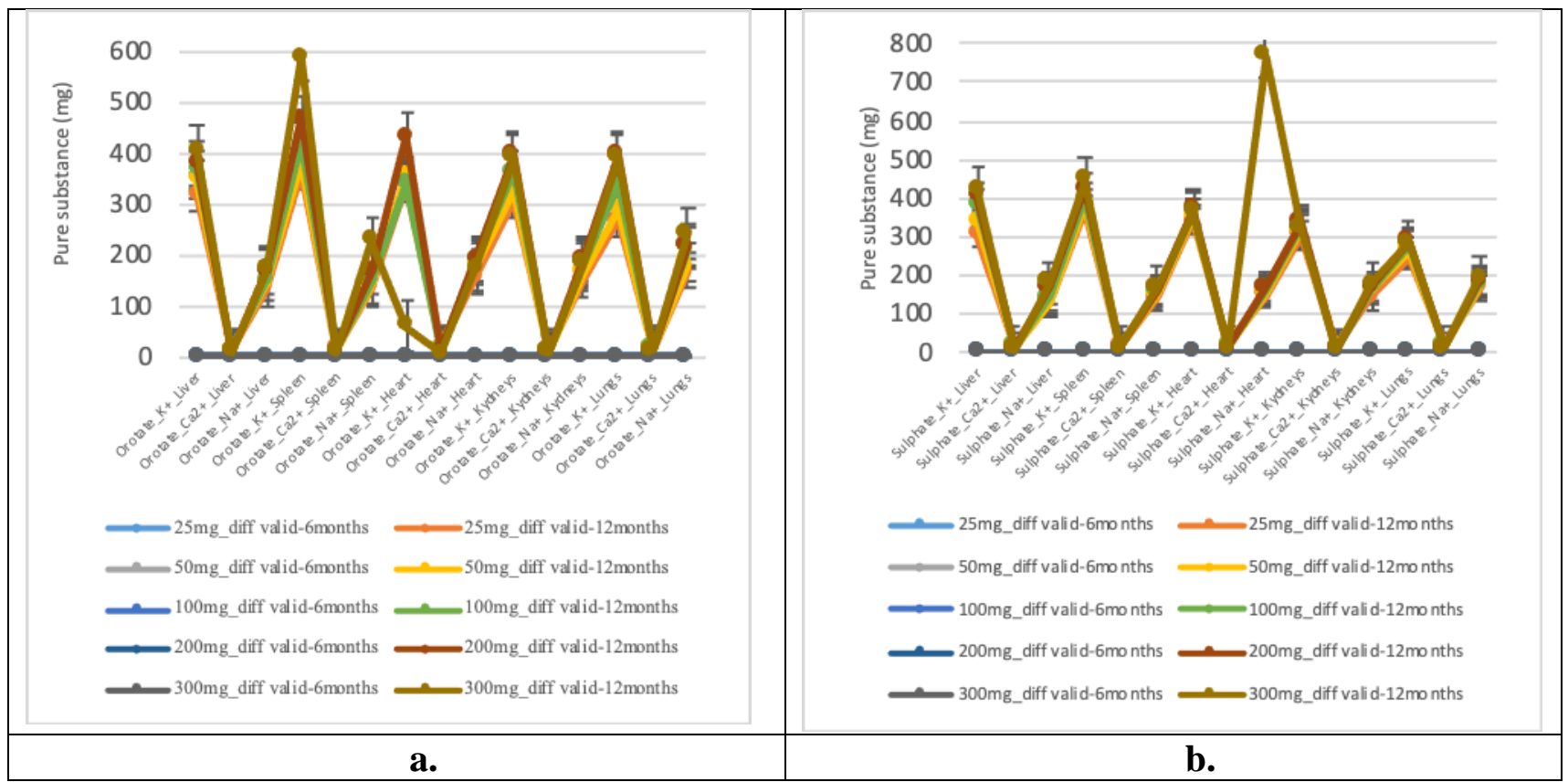




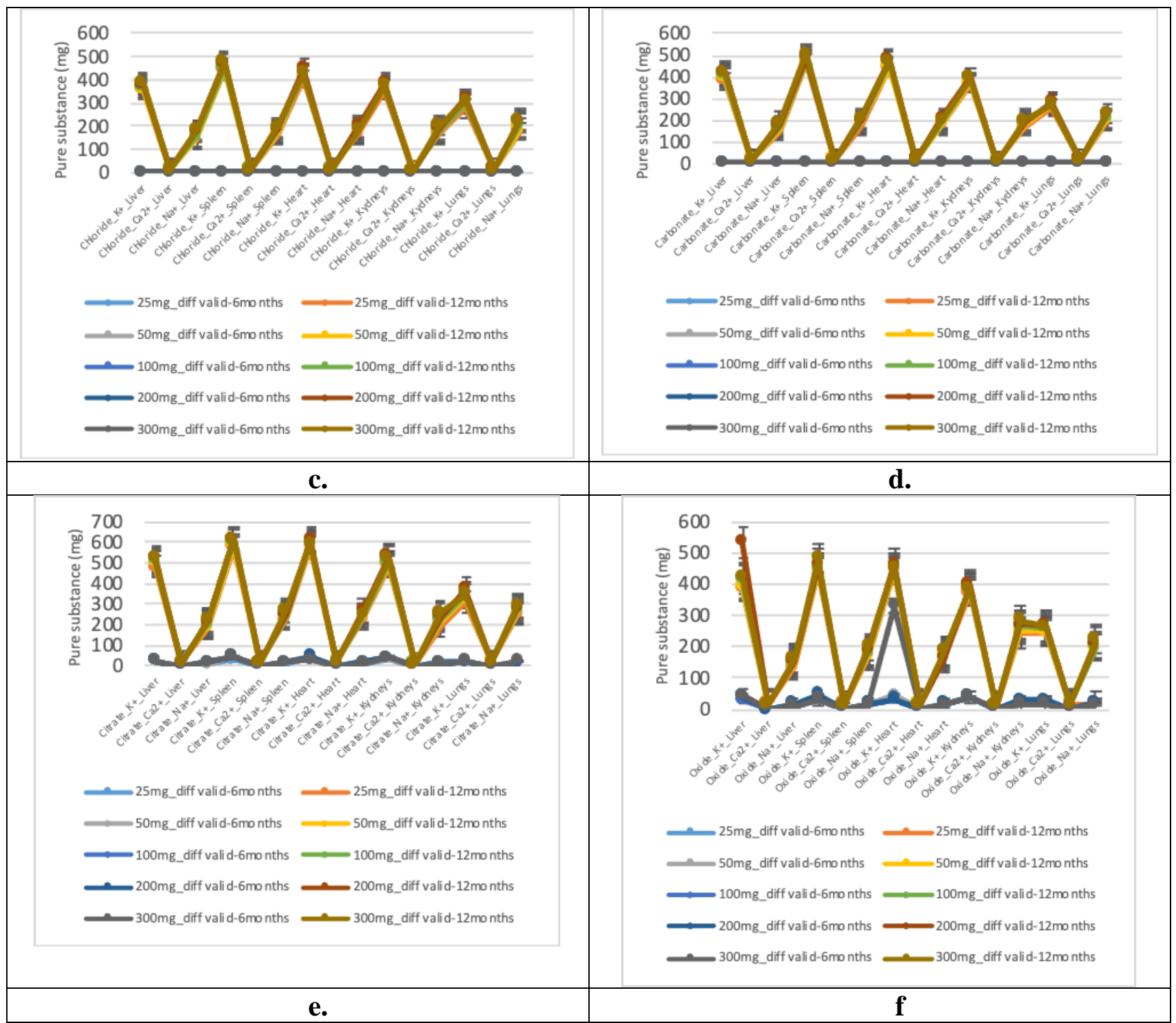

Figure 2. Differences between the various types of $\mathrm{Mg}$ concentration in organs, after administration of magnesium compounds within shelf life and after it was exceeded with 6 / 12 months: a. orotate;

b. sulphate; c. chloride; d. carbonate; e. citrate; f. oxide. The first line close to zero is representing the difference between the magnesium compounds absorption in shelf life and after 6 months it was

exceeded. So, there are almost no differences registered between this 2 time points.

The second line, which is above zero, represents the differences registered in the magnesium compounds absorption power after the shelf life exceeded with 12 months. In this case, significant differences can be observed

So, in Figure 1, the first line group close to zero $(0-10 \mathrm{mg})$ is describing the data variance regarding the difference between the magnesium compounds within shelf life and after 6 months exceeding it; the second line group (between 18-90 mg) is describing the difference between the $\mathrm{Mg}$ compounds within shelf life and after 12 months from expiration. From this chart, it can be stated that in the first 6 month after the shelf life passed, there are no major differences registered in the magnesium absorption power but there are major differences registered after the shelf life was exceeded with 12 months. In Figure 2, it was used the same reasoning, but it is presented each $\mathrm{Mg}$ compound and its effect on the tested organs. It was obtained the same conclusion as in Figure 1.

In the end of this research, the different $\mathrm{Mg}$ compounds absorption levels were measured in the studied organs. In this purpose, the ANOVA One Way and the Kruskal Wallis tests were performed. 
Both tests presented the same conclusions. For the compounds being in shelf life, the following results were obtained: for the heart - very significant differences $(p=0.004)$, the lowest value being obtained in the case of oxide and the highest value in the case of citrate; for spleen - insignificant differences $(\mathrm{p}=0.116)$, the lowest value resulting in the case of sulphate and the highest value in the case of citrate; for kidneys, lungs and liver, extremely significant differences were highlighted $(\mathrm{p}<0.001)$, the lowest value for each organ was obtained in the case of oxide and the highest value in the case of citrate.

After the shelf life was exceeded with 6 months, the same analysis was performed, and the following results were obtained: for heart - very significant differences $(\mathrm{p}=0.006)$; for spleen - insignificant differences ( $\mathrm{p}=0.138)$; for kidneys, lungs and liver - extremely significant differences $(\mathrm{p}<0.001)$.

In all the organs the lowest value was obtained in the case of oxide and the highest value in the case of citrate. In the last tested scenarios, after the shelf life was exceeded with 12 months, the same analysis was run again; the following results were obtained: for heart, kidneys, lungs and liver - extremely significant differences $(\mathrm{p}<0.001)$ and for spleen - very significant differences $(\mathrm{p}=0.002)$. In all the organs the lowest value was obtained in the case of oxide and the highest value in the case of orotate. All the results are plotted in Figures 3-5.

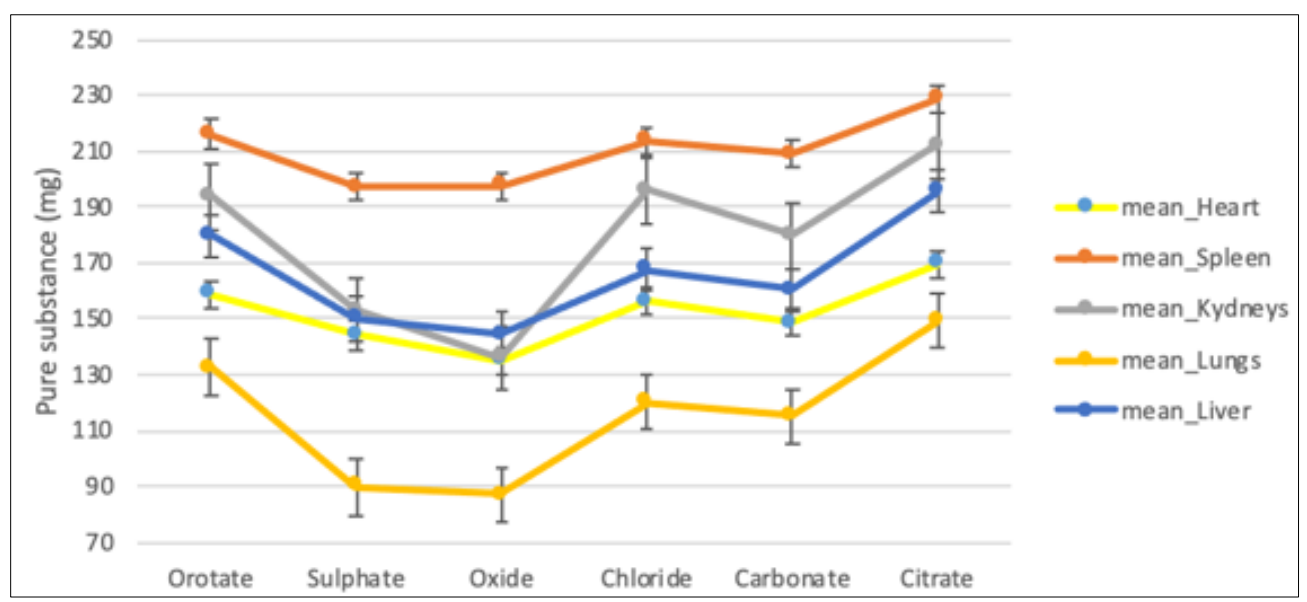

Figure 3. The absorption levels of $\mathrm{Mg}$ compounds within the shelf life, in different organs

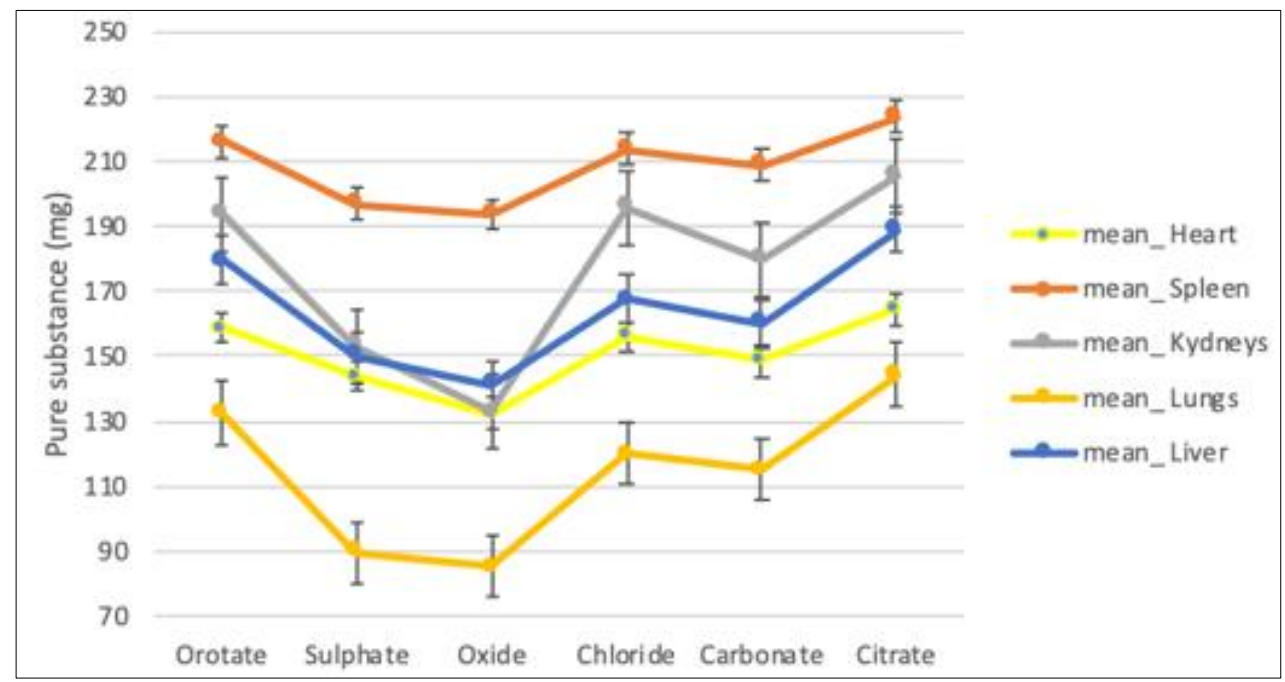

Figure 4. $\mathrm{Mg}$ compounds absorption levels, in different organs, at 6 months after the shelf life was exceeded 


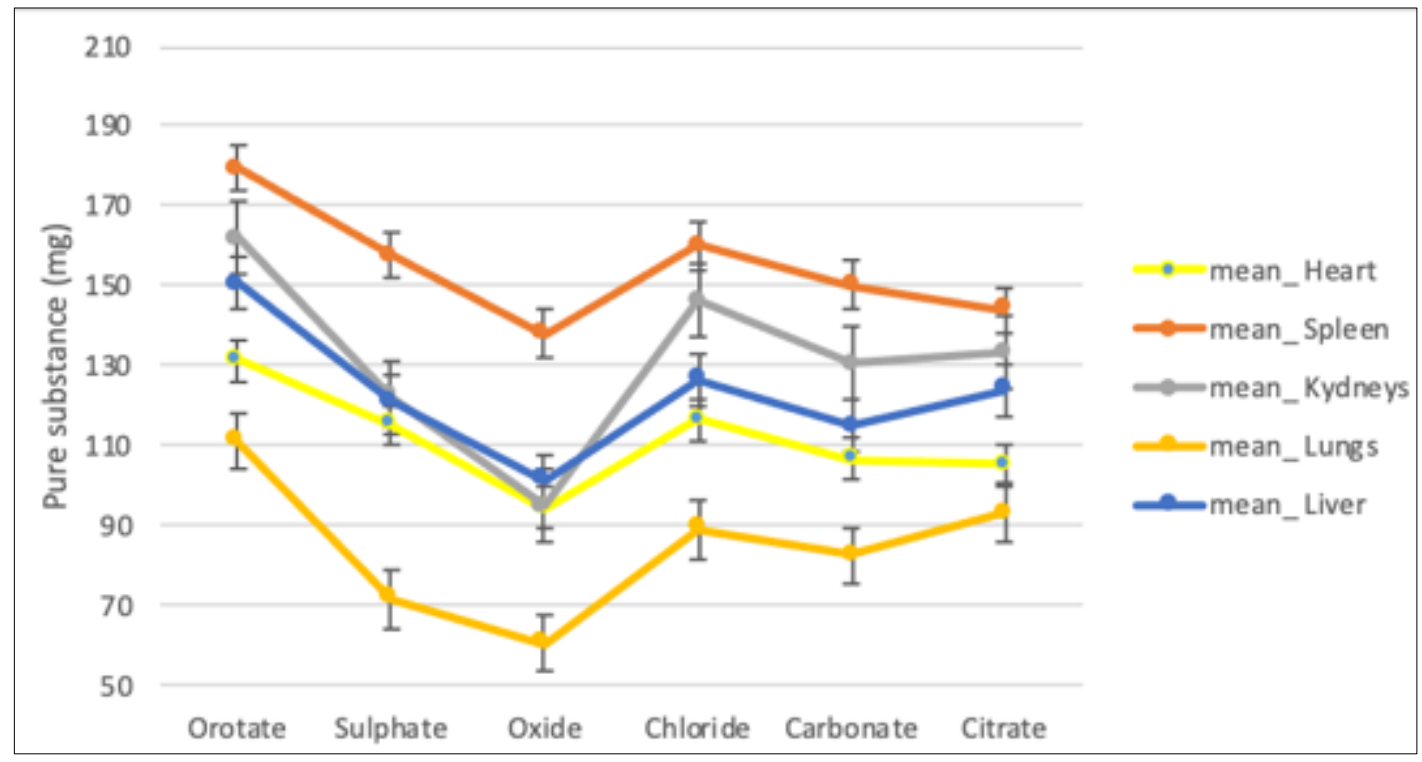

Figure 5. $\mathrm{Mg}$ compounds absorption levels, in different organs, at 12 months after the shelf life was exceeded

Considering the importance of magnesium for the human body, as well as the deficient supply of magnesium due to soil pollution and the excessive use of chemicals as fertilizers [19-22], the use of food supplements containing magnesium is increasingly common in medical practice. Dietary intake of low magnesium leads to low serum magnesium concentrations and this phenomenon has been associated with an increased risk of cardiovascular diseases, osteoporosis and metabolic disorders, including metabolic syndrome and high blood pressure. Some individuals are more susceptible to magnesium deficiency, especially those with gastrointestinal or renal disorders and the elderly [23,24]. Previous research has shown that the source of magnesium used to treat hypomagnesemia significantly influences the bioavailability of magnesium both intracellularly and extracellularly $[14,15]$. The results of this study associate the administration of magnesium citrate with the highest rate of absorption at the intracellular level, at the level of all studied organs regardless of concentration and the lowest rate with was associated with magnesium oxide.

Various particular transporters that control the cellular circulation of magnesium were discovered. Magnesium is transported in the cell through $\mathrm{Mg}^{2+}$ /anion cotransport, favored by cations channels and the electrochemical gradient of $\mathrm{Na}^{+}$. There were discovered eight cation channels like: magnesium transporter 1 (MagT1), the mitochondrial RNA splicing 2 protein (Mrs2p), members 1 and 2 (SLC41A1, SLC41A2) channels, transient receptor potential mela statin cation channels 6 and 7 (TRPM6, TRPM7), ancient conserved domain protein 2 (ACDP2), paracellin-1 and the human solute carrier family 41 [25]. The most selective channel for magnesium, TRPM7, is present in blood vessels, brain, heart, liver, spleen, lungs and intestines. This channel has an essential role in adjusting intracellular magnesium levels as well as in the function and survival of the cell [26]. The TRPM6 channel has the role of adjusting the total amount of magnesium in the body through intestines and kidneys [27]. The channels SLC41A1, Mrs2p and SCL41A2 have a regulatory role for the cardiovascular, metabolic and neurological functions, being involved in the magnesium circulation in the mitochondria [28]. The magnesium flow generates various exchanges like $\mathrm{Mn}^{2+} / \mathrm{Mg}^{2+}$ antiporter, $\mathrm{Na}^{+} / \mathrm{Mg}^{2+}, \mathrm{Cl}^{-}$ $/ \mathrm{Mg}^{2+}$ cotransporter and $\mathrm{Ca}^{2+} / \mathrm{Mg}^{2+}$. The most significant exchanger is $\mathrm{Na}^{+} / \mathrm{Mg}^{2+}$, found in various cells like cardiac and vascular smooth cells. There are various factors like insulin, vasopressin and angiotensin II that influence the activity of this exchanger [29].

It is important to precisely adjust the levels of cellular magnesium. Low concentrations of magnesium in the blood lead to low concentrations of calcium in the blood and negatively affect the action of parathyroid hormone (PTH), disrupting some of the effects of vitamin D [26, 28]. Many of the previous 
studies mainly focused on the diseases caused by hypomagnesemia and the therapeutic role of magnesium. However, many diseases occur due to the modern diet with magnesium deficiency, therefore the preventive role of magnesium is important in avoiding possible diseases. An increase of $0.2 \mathrm{mmol} / \mathrm{L}$ in serum magnesium was associated with $30 \%$ lower risk of cardiovascular diseases. Used in the prophylaxis of postoperative atrial arrhythmia after coronary artery bypass grafting, magnesium was found to have an adjunctive role in the therapy with antiarrhythmics used in these conditions. Following different studies on patients who underwent surgery, as a result of cardiovascular disease, it was shown that after the administration of intravenous magnesium infusions, the postoperative atrial arrhythmia was significantly reduced in the treated patients compared to the untreated patients [30,31]. Some studies indicate that following the administration of magnesium these patients have obtained clinical results comparable to those obtained following the administration of antiarrhythmic drugs [32,33]. Also, the results of some studies indicate that intravenous magnesium administration in the case of myocardial infarction could reduce the risk of death. The study was performed on 2,316 patients and showed a significant reduction in mortality in the group of patients who received intravenous magnesium sulfate within $24 \mathrm{~h}$ from suspected myocardial infarction (7.8\% total mortality in the experimental group vs. $10.3 \%$ causal mortality in the placebo group) $[34,35]$.

To be useful, the pharmaceutical preparations with magnesium used for therapeutic or prophylactic purposes, must have a high bioavailability, be safe and have high stability over time. In this study, the absorption level of the $\mathrm{Mg}$ compounds is inversely proportional with the shelf life so that when it is exceeded, the absorption of the $\mathrm{Mg}$ compounds is reduced. Also, an interesting aspect must be mentioned after the 12 months of study: the orotate is the most constant compound for all the mentioned organs. As well, orotate absorption properties remained almost the same even if the shelf life was exceeded with 12 months. At 6 months, the intracellular concentrations of magnesium were lower with up to $4 \%$ (in the case of magnesium oxide and citrate) and remained unchanged for the other salts. As side effect, a slight laxative effect was observed following the administration of magnesium citrate that was more pronounced in the case of magnesium sulfate. Regarding the study of the stability of the compounds at 12 months after the shelf life, a decrease of the intracellular magnesium level was observed, with a percentage of more than $10 \%$ for all the analyzed substances, except for the orotate, indicating that the chemical structure of these salts was modified over time and these preparations no longer correspond in terms of quality. Considering that magnesium is a resistant metallic ion, the chemical instability of the studied compounds is not due to magnesium itself but to its salts that have a relevant role in the intracellular penetration of magnesium. Also, magnesium being essential in the metabolic processes throughout the body, when there is a decrease in its concentration, it is imperative that a pharmaceutical product containing a magnesium salt to be administered, thus allowing a higher concentration to be reached not just in serum but also intracellularly.

\section{Conclusions}

The data obtained demonstrated a good stability of the tested substances, indicated by maintaining the cellular uptake rate, including the compounds being in 6 months after expiration date. The magnesium absorption at the intracellular level had the best rate when administered as citrate, regardless of quantities, both within the shelf life and 6 months after the expiry date, but at 12 months after the expiry date the absorption decreases significantly. The results obtained proved that the only magnesium compound with an absorption rate without significant variations at 12 months after expiration vs. the shelf life is the orotate.

\section{References}

1.MARTIN, K.J., GONZALEZ, E.A., SLATOPOLSKY, E., Clinical consequences and management of hypomagnesemia, J. Am. Soc. Nephrol., 20(11), 2009, 2291-2295. doi: 10.1681/ASN.2007111194.

2.VORMANN. J., Magnesium: nutrition and metabolism, Mol. Aspects. Med., 24, 2003, $27-37$. doi: 10.1016/S0098-2997(02)00089-4 
3.RYAN, M.F. The role of magnesium in clinical biochemistry: an overview. Ann. Clin. Biochem., 28(Pt1), 1991, 19-26.

4.SUN, Y., SELVARAJ, S., VARMA, A., DERRY, S., SAHMOUN, A.E., SINGH, B.B., Increase in serum $\mathrm{Ca} 2+/ \mathrm{Mg} 2+$ ratio promotes proliferation of prostate cancer cells by activating TRPM7 channels, J. Biol. Chem., 288(1), 2013, 255-263. doi: 10.1074/jbc.M112.393918

5.DEL GOBBO, L.C., SONG, Y., POIRIER, P., DEWAILLY, E., ELIN, R.J., EGELAND, G.M., Low serum magnesium concentrations are associated with a high prevalence of premature ventricular complexes in obese adults with type 2 diabetes, Cardiovasc. Diabetol., 11(1), 2012, 23.

doi: 10.1186/1475-2840-11-23.

6.EFSTRATIADIS, G., SARIGIANNI, M., GOUGOURELAS, I., Hypomagnesemia and cardiovascular system, Hippokratia, 10(4), 2006, 147-152.

7.ANGKANANARD, T., ANOTHAISINTAWEE, T., EURSIRIWAN, S., GORELIK, O., MCEVOY, M., ATTIA, J., THAKKINSTIAN, A., The association of serum magnesium and mortality outcomes in heart failure patients: A systematic review and meta-analysis, Medicine, 95(50), 2016, e5406.

https://doi.org/10.1097/MD.0000000000005406

8.ABDEL-DAIM, M.M., EL-TAWIL, O.S., BUNGAU, S.G., ATANASOV, A.G., Applications of Antioxidants in Metabolic Disorders and Degenerative Diseases: Mechanistic Approach, Oxid. Med. Cell. Longev., 2019, 2019, 4179676. https://doi.org/10.1155/2019/4179676.

9.CEREMUZYNSKI, L., GEBALSKA, J., WOLK, R., MAKOWSKA, E., Hypomagnesemia in heart failure with ventricular arrhythmias. Beneficial effects of magnesium supplementation, J. Intern. Med., 247(1), 2000, 78-86. doi: 10.1046/j.1365-2796.2000.00585.x

10.WESTER, P.O., DYCKNER, T. Intracellular electrolytes in cardiac failure. Acta. Med. Scan., 219(707), 1986, 33-36. doi: 10.1111/j.0954-6820.1986.tb18112.x

11.AZIZ, H.S., BLAMOUN, A.I., SHUBAIR, M.K., ISMAIL, M.M., DEBARI, V.A., KHAN, M.A., Serum magnesium levels and acute exacerbation of chronic obstructive pulmonary disease: a retrospective study, Ann. Clin. Lab. Sci., 35(4), 2005, 423-427.

12.BHATT, S.P., KHANDELWAL, P., NANDA, S., STOLTZFUS, J.C., FIORAVANTI, G.T., Serum magnesium is an independent predictor of frequent readmissions due to acute exacerbation of chronic obstructive pulmonary disease, Resp. Med., 102(7), 2008, 999-1003.

13.SHIVANTHAN, M.C., RAJAPAKSE, S., Magnesium for acute exacerbation of chronic obstructive pulmonary disease: a systematic review of randomised trials, Ann. Thorac. Med. 9(2), 2014, 77-80.

doi: 10.4103/1817-1737.128844.

14.MOISA, C., CADAR, O., BARABAS, R., VICAȘ, L., HOAGHIA, A., LEVEI, E., JURCA, C., BERCE, C., Influence of magnesium compounds on sodium, potassium and calcium levels in different mice organs, Farmacia, 67(2), 2019, 274-281. doi: 10.31925/farmacia.2019.2.11

15.MOISA, C., HOAGHIA, M., SIMEDRU, D., CADAR, O. Influence of tablet formulation in vitro release of magnesium, Stud. Univ. Babes-Bol., LXI(3), 2016, 441-449.

16.BUNGAU, S., TIT, D.M., FODOR, K., CIOCA, G., AGOP, M., IOVAN, C., NISTOR CSEPPENTO, D.C., BUMBU, A., BUSTEA, C., Aspects regarding the pharmaceutical waste management in Romania, Sustainability, 10, 2018, 2788. doi:10.3390/su10082788

17.ZAHA, D.C., BUNGAU, S., SEliM, A., TIT, D.M., VESA, CM, POPA, A.R,. PANTIS, C., MAGHIAR, O.A., BRATU, O.G., FURAU, C., et al., What antibiotics for what pathogens? The sensitivity spectrum of isolated strains in an intensive care unit, Sci. Tot. Environ., 687, 2019, 118-127. https://doi.org/10.1016/j.scitotenv.2019.06.076.

18.ZHAO, D., WANG, T., NAHAN, K., GUO, X., ZHANG, Z., DONG, Z., CHEN, S., CHOU, D.T., HONG, D., KUMTA, P.N., HEINMAN, W.R., In vivo characterization of magnesium alloy biodegradation using electrochemical $\mathrm{H}_{2}$ monitoring, ICP-MS and XPS, Acta Biomater., 50, 2017, 556565. doi: 10.1016/j.actbio.2017.01.024. 
19.GITEA, M.A., BUNGAU, S., GITEA, D., PURZA, L., NEMETH, S., SAMUEL, A.D., BADEA, G. TIT D.M., The consequences of excessive chemicalization on fruits quality, Rev. Chim., 69(6), 2018,1303-1308.

20.SAMUEL, A.D., BREJEA, R., DOMUTA, C., BUNGAU, S., CENUSA, N., TIT, D.M., Enzymatic indicators of soil quality, J. Environ. Prot. Ecol., 18(3), 2017, 871-878.

21.SAMUEL, A.D., BUNGAU, S., TIT, D.M., MELINTE (FRUNZULICA), C.E., PURZA, L., BADEA, G.E., Effects of long term application of organic and mineral fertilizers on soil enzymes, Rev. Chim., 69(10), 2018, 2608-2612.

22.SAMUEL, A.D., TIT, D.M., MELINTE (FRUNZULICA), C.E., IOVAN, C., PURZA, L., GITEA, M., BUNGAU, S., Enzymological and physicochemical evaluation of the effects of soil management practices, Rev. Chim., 68(10), 2017, 2243-2247.

23.FINE, K.D., SANTA ANA, C.A., PORTER, J.L., FORDTRAN, J.S., Intestinal absorption of magnesium from food and supplements, J. Clin. Invest., 88, 1991, 396-402.

24.RANADE, V.V., SOMBERG, J.C., Bioavailability and pharmacokinetics of magnesium after administration of magnesium salts to humans, Am. J. Ther., 8, 2001, 345-357.

25.SONTIA, B., TOUYZ, R.M., Magnesium transport in hypertension, Pathophysiol., 14(3-4), 2007, 205-211. doi:10.1016/j.pathophys.2007.09.005.

26.MONTEILH-ZOLLER, M.K., HERMOSURA, M.C., NADLER, M.J.S., SCHARENBERG, A.M., PENNER, R., FLEIG, A., TRPM7 provides an ion channel mechanism for cellular entry of trace metal ions, J. Gen. Psychol., 121(1), 2012, 49-60. doi:10.1085/jgp.20028740.

27.SCHLINGMANN, K.P., GUDERMANN, T., A critical role of TRPM channel-kinase for human magnesium transport, J. Physiol., 566(2), 2005, 301-308. doi: 10.1113/jphysiol.2004.080200.

28.PILCHOVA, I., KLACANOVA, K., TATARKOVA, Z., KAPLAN, P., RACAY, P., The involvement of $\mathrm{Mg}^{2+}$ in regulation of cellular and mitochondrial functions, Oxid. Med. Cell. Longev., 2017, 2017, 6797460, doi: 10.1155/2017/6797460.

29.GOLD, M.E., BUGA, G.M., WOOD, K.S., BYRNS, R.E., CHAUDHURI, G., IGNARRO, L.J., Antagonistic modulatory roles of magnesium and calcium on release of endothelium-derived relaxing factor and smooth muscle tone, Circ. Res., 66(2), 1990, 355-366. doi: 10.1161/01.res.66.2.355.

30.CHIUVE, S.E., KORNGOLD, E.C., JANUZZI, JR. J.L., GANTZER, M.L., ALBERT, C.M., Plasma and dietary magnesium and risk of sudden cardiac death in women, Am. J. Clin. Nutr., 93(2), 2011, 253260. doi: 10.3945/ajen.110.002253

31.JOOSTEN, M.M., GANSEVOORT, R.T., MUKAMAL, K.J., VAN DER HARST, P., GELEIJNSE, J.M., FESKENS, E.J.M., NAVIS, G., BAKKER, S.J.L. Urinary and plasma magnesium and risk of ischemic heart disease, Am. J. Clin. Nutr., 97(6), 2013, 1299-306. doi: 10.3945/ajen.112.054114.

32.LARSSON, S.C., ORSINI, N., WOLK, A., Dietary magnesium intake and risk of stroke: a metaanalysis of prospective studies, Am. J. Clin. Nutr., 95(2), 2012, 362-366. doi: 10.3945/ajen.111.022376. 33.SONG, Y., LIU, S., Magnesium for cardiovascular health: time for intervention. Am. J. Clin. Nutr., 95(2), 2012, 269-270. doi: 10.3945/ajen.111.022376.

34.DEL GOBBO, L.C., IMAMURA, F., WU, J.H.Y., OTTO, M.C.O., CHIUVE, S.E., MOZAFFARIAN, D., Circulating and dietary magnesium and risk of cardiovascular disease: a systematic review and meta-analysis of prospective studies, Am. J. Clin. Nutr., 98(1), 2013, 160-173. doi: $10.3945 / a j$ cn.112.053132.

35.WOODS, K.L., FLETCHER, S., ROFFE, C., HAIDER, Y., Intravenous magnesium sulphate in suspected acute myocardial infarction: results of the second Leicester Intravenous Magnesium Intervention Trial (LIMIT-2), Lancet, 339(8809), 1992, 1553-1558.

doi:10.1016/0140-6736(92)91828-v

$\overline{\text { Manuscript received: } 1.07 .2020}$ 